\title{
A boy with developmental delay and mosaic supernumerary inv dup(5)(p15.33p15.1) leading to distal $5 p$ tetrasomy - case report and review of the literature
}

Pavel Tesner ${ }^{1 *}$ (D, Jana Drabova ${ }^{1}$, Miroslav Stolfa', Martin Kudr², Martin Kyncl', Veronika Moslerova', Drahuse Novotna', Radka Kremlikova Pourova', Eduard Kocarek', Tereza Rasplickova', Zdenek Sedlacek ${ }^{1}$ and Marketa Vlckova ${ }^{1}$

\begin{abstract}
Background: With only 11 patients reported, $5 p$ tetrasomy belongs to rare postnatal findings. Most cases are due to small supernumerary marker chromosomes (sSMCs) or isochromosomes. The patients share common but unspecific symptoms such as developmental delay, seizures, ventriculomegaly, hypotonia, and fifth finger clinodactyly. Simple interstitial duplications leading to trisomies of parts of $5 p$ are much more frequent and better described. Duplications encompassing 5p13.2 cause a defined syndrome with macrocephaly, distinct facial phenotype, heart defects, talipes equinovarus, feeding difficulties, respiratory distress and anomalies of the central nervous system, developmental delay and hypotonia.

Case presentation: We present a boy with dysmorphic features, developmental delay, intellectual disability and congenital anomalies, and a mosaic sSMC inv dup(5)(p15.33p15.1). He is the fourth and the oldest reported patient with distal $5 p$ tetrasomy. His level of mosaicism was significantly different in lymphocytes (13.2\%) and buccal cells (64.7\%). The amplification in our patient is smaller than that in the three previously published patients but the only phenotype difference is the absence of seizures in our patient.

Conclusions: Our observations indicate that for the assessment of prognosis, especially with respect to intellectual functioning, the level of mosaicism could be more important than the extent of amplification and the number of extra copies. Evaluation of the phenotypical effect of rare chromosomal aberrations is challenging and each additional case is valuable for refinement of the genotype-phenotype correlation. Moreover, our patient demonstrates that if the phenotype is severe and if the level of SSMC mosaicism is low in lymphocytes, other tissues should be tested.
\end{abstract}

Keywords: $5 p$ tetrasomy, Marker chromosome, Mosaicism, Intellectual disability

\footnotetext{
* Correspondence: pavel.tesner@|fmotol.cuni.cz

${ }^{1}$ Department of Biology and Medical Genetics, Charles University 2nd Faculty

of Medicine and University Hospital Motol, V Uvalu 84, 15006 Prague 5,

Czech Republic

Full list of author information is available at the end of the article
}

(c) The Author(s). 2018 Open Access This article is distributed under the terms of the Creative Commons Attribution 4.0 International License (http://creativecommons.org/licenses/by/4.0/), which permits unrestricted use, distribution, and reproduction in any medium, provided you give appropriate credit to the original author(s) and the source, provide a link to the Creative Commons license, and indicate if changes were made. The Creative Commons Public Domain Dedication waiver (http://creativecommons.org/publicdomain/zero/1.0/) applies to the data made available in this article, unless otherwise stated. 


\section{Background}

Tetrasomies of a part or the whole $5 p$ belong to rare postnatal findings and can be the result of a small supernumerary marker chromosome (sSMC) with inverted duplication (inv dup) or an isochromosome. Clinical outcomes of sSMCs vary from an unaffected to a severely affected status with major anomalies and intellectual disability (ID). sSMCs are often present in mosaics and can even be absent in some tissues. The clinical manifestation is frequently influenced by the level of mosaicism in specific tissues [1].

Only 11 postnatal patients of $5 p$ tetrasomy have been reported, seven with supernumerary i(5)(p10) [2-8], three with amplification of the distal part of $5 p$ - one interstitial triplication [9] and two supernumerary inv dup $[10,11]$, and one patient had proximal $5 p$ tetrasomy but his phenotype description and sSMC characterization were rather incomplete [12]. The features of 5p tetrasomy are developmental delay, seizures, ventriculomegaly, hypotonia, short stature or growth delay, and fifth finger clinodactyly [11]. A single transverse palmar crease, recurrent infections, abnormalities of the diaphragm, abnormalities of the pinna, microretrognathia, abnormalities of the philtrum and thin upper lip vermilion are also frequently observed. Interestingly, the phenotype seems to be rather similar irrespective of whether the whole $5 p$ or just its distal part is amplified.

In contrast to $5 p$ tetrasomies, partial or complete $5 p$ trisomies are much more frequent. Proximal 5p trisomies are associated with a specific phenotype with macrocephaly, facial anomalies (upslanted palpebral fissures, hypertelorism, epicanthus, depressed nasal bridge, midface retrusion, micrognathia, and abnormality of the pinna), short neck, hypoplasia of the abdominal wall musculature, congenital heart defects, talipes equinovarus, feeding difficulties, respiratory distress, recurrent respiratory infections, and anomalies of the central nervous system (CNS), especially ventriculomegaly. Generalized hypotonia, seizures and ID are also common [13]. The critical region for this phenotype was primarily placed to 5p11-p13 by Chia et al. [14] and later refined to 5p13.1-p13.3 by Loscalzo et al. [15]. The 5p13.2 duplication syndrome was finally defined by Yan et al. [16], and NIPBL was suggested as its critical gene [17].

We present a 5-year-old boy with dysmorphic features, feeding difficulties, hypotonia, developmental delay, ID, autistic features, and mosaic sSMC inv dup(5)(p15. $33 \mathrm{p} 15.1)$ resulting in tetrasomy of distal $5 \mathrm{p}$ not involving the 5 p13.2 region. We compared the genotype and phenotype of our patient with previously described patients of $5 p$ tetrasomy and reviewed the literature for clinical effects of tetrasomy and trisomy of distinct parts of $5 \mathrm{p}$. We found just slight and non-specific differences among the phenotypes of the patients compared. Our observations indicate that for the assessment of prognosis, especially with respect to intellectual functioning, the level of mosaicism could be more important than the extent of the region amplified and the number of extra copies.

\section{Case presentation \\ Clinical report}

The boy was born via spontaneous delivery from the second uneventful pregnancy to healthy unrelated Caucasian parents. The age of the mother and the father was 31 and 32 years, respectively. Birth weight was $3650 \mathrm{~g}$ (82nd centile) and birth length was $53 \mathrm{~cm}$ (87th centile). No congenital anomalies were observed in the newborn, and the neonatal period was unremarkable. During the infant period the boy suffered from feeding difficulties and recurrent upper airways infections. His psychomotor development was delayed. Pyelectasia, foramen ovale apertum and hiatal hernia were detected at the age of 14 months, and brain MRI revealed a cyst in posterior cranial fossa.

He was examined again at the age of 3 years and 5 months due to global developmental delay. He was not able to walk but he started to stand with support. The speech was absent and he used only vocalizations. He had problems with chewing and he could eat only mashed food. His parents described frequent aggressive behavior with biting. Hypotonia (central hypotonic syndrome), hypermobility of joints and pedes planovalgi were also present. His height was $96 \mathrm{~cm}$ (11th centile), weight was $13.5 \mathrm{~kg}$ (7th centile) and head circumference was $52.5 \mathrm{~cm}$ (96th centile). Dysmorphic features included dolichocephaly, frontal bossing, low set ears, abnormality of the pinna, hypotelorism, downslanted palpebral fissures, epicanthus, depressed nasal bridge, low hanging columella, long philtrum, thin upper lip vermilion, short chin, slight midface retrusion, single transverse palmar crease on the right hand, pectus excavatum, and kyphosis (Fig. 1a, b).

At the last examination at the age of 5 years and 1 month his height was $110 \mathrm{~cm}$ (18th centile; however, according to growth prediction from the mid parent height, the height of the boy would be expected to be around 97th centile, and thus the actual observation might rather indicate a more significant growth delay), weight was $15.5 \mathrm{~kg}$ (2th centile) and head circumference was $54 \mathrm{~cm}$ (95th centile). Speech was still absent and feeding and chewing difficulties persisted, but the boy was able to walk independently. He showed symptoms of an autism spectrum disorder such as stereotypical hand movements, frequent bruxism and a very sporadic eye contact. Macrocephaly, dolichocephaly, central hypotonic syndrome and hypermobility of the joints persisted. Pedes planovalgi were accompanied by valgus 


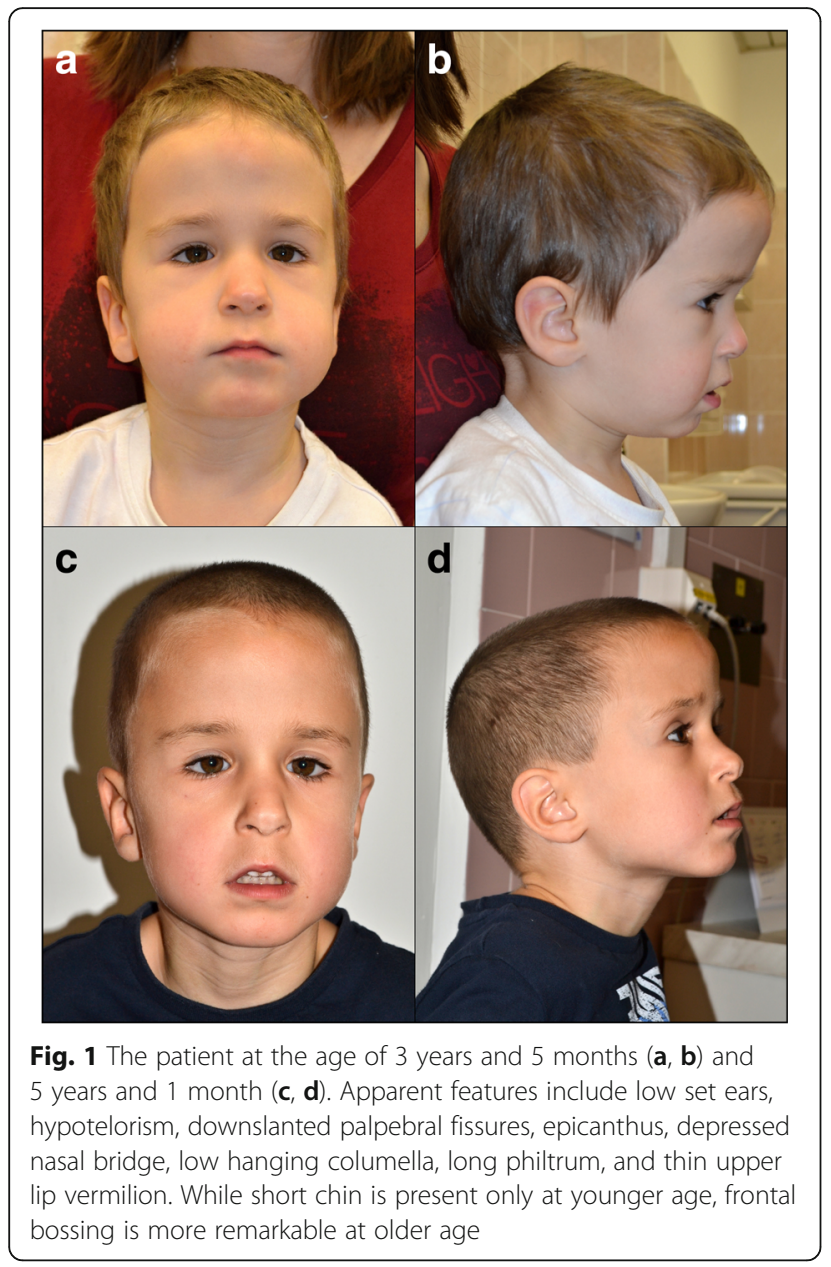

deformity of the knees. In addition, a small umbilical hernia was present. Midface retrusion and short chin observed previously were not present, but the forehead was even more prominent (Fig. 1c, d).

\section{Laboratory analysis}

The research was prospectively reviewed and approved by a duly constituted ethics committee. Informed consent was obtained from the parents of the patient. Examination of G-banded chromosomes from peripheral blood lymphocytes was performed using standard protocols. For fluorescence in situ hybridization (FISH) analysis of blood lymphocytes and buccal cells, Cytocell Aquarius Cri-duchat and SOTOS Probe Combination (LPU 013) (Oxford Gene Technology, UK) was used. High-resolution array comparative genomic hybridization $(\mathrm{aCGH})$ and single nucleotide polymorphism (SNP) analysis of the lymphocyte genomic DNA isolated using AutoGen Flex STAR (Autogen, USA) employed the SurePrint G3 ISCA V2 CGH 8x60K Microarray and the SurePrint G3 ISCA CGH
+ SNP 4x180K Microarray, respectively, according to the protocol of the manufacturer (Agilent Genomics, USA).

\section{Results}

The patient had a mosaic sSMC and karyotype mos 47,XY,+mar[10]/46,XY[28] (Fig. 2a). Parental karyotypes were normal and the sSMC occurred de novo. aCGH analysis of the patient revealed gain of material in 5p15.33p15. 1, in the region chr5:22149_15009591 (hg19) (Fig. 2b). FISH analysis confirmed the origin of the sSMC from $5 \mathrm{p} 15$. 33p15.1 and revealed its inv dup structure (Fig. 2c), with the final karyotype mos 47,XY,+dup(5)(pter $\rightarrow$ p15.1::p15. $1 \rightarrow$ pter)dn[10]/46,XY[28]. The region of tetrasomy was $15 \mathrm{Mb}$ long and encompassed 137 genes including 54 protein-coding genes, of which 14 are known diseasecausing genes (Additional file 1). Considering the tetrasomic nature of the aberration, the mean $\log _{2}$ ratio of 0.176 observed in aCGH indicated a mosaic of $13.0 \%$ according to the formula by Valli et al. [18]. FISH analysis of 409 cell nuclei of peripheral lymphocytes showed the sSMC in $13.2 \%$ of cells. In contrast, interphase FISH analysis of 312 nuclei of buccal mucosa cells showed the sSMC in $64.7 \%$ of cells. SNP array CGH analysis identified 71 at least partly informative SNPs in the interval of the $5 p$ tetrasomy allowing to deduce the parental origin of the sSMC. The analysis was complicated by the low level of mosaicism of the sSMC in lymphocytes, and the almost $1 \%$ error rate of the array as indicated by genome-wide discrepancies with Mendelian inheritance. Nevertheless, 18 informative SNPs clearly indicated the paternal origin of the sSMC, and 51 additional SNPs were not at odds with this scenario. Of the SNPs which could discriminate between the paternal alleles, 10 clearly indicated that both SNP alleles on the SSMC were identical to the allele present on the normal chromosome 5 inherited by the patient from the father, and 8 additional SNPs were not at odds with this scenario (showing that the sSMC alleles could originate either from the paternal chromosome 5 inherited by the patient, or from the other paternal chromosome 5). Of the 51 SNPs which were not at odds with the paternal origin, 20 showed alleles identical to the sSMC and the normal paternal chromosome 5, and 29 could not discriminate between the two scenarios.

\section{Discussion and conclusions}

According to literature reports, isochromosomes of the whole $5 \mathrm{p}(\mathrm{i}(5)(\mathrm{p} 10))$ [2-8] are more frequent than inv dups of distal $5 p$ [9-11]. Our patient is the fourth and the oldest case with tetrasomy of distal $5 \mathrm{p}$. He is the only patient old enough to allow proper evaluation of his intellectual functioning, not only developmental delay, but also of all other features. 


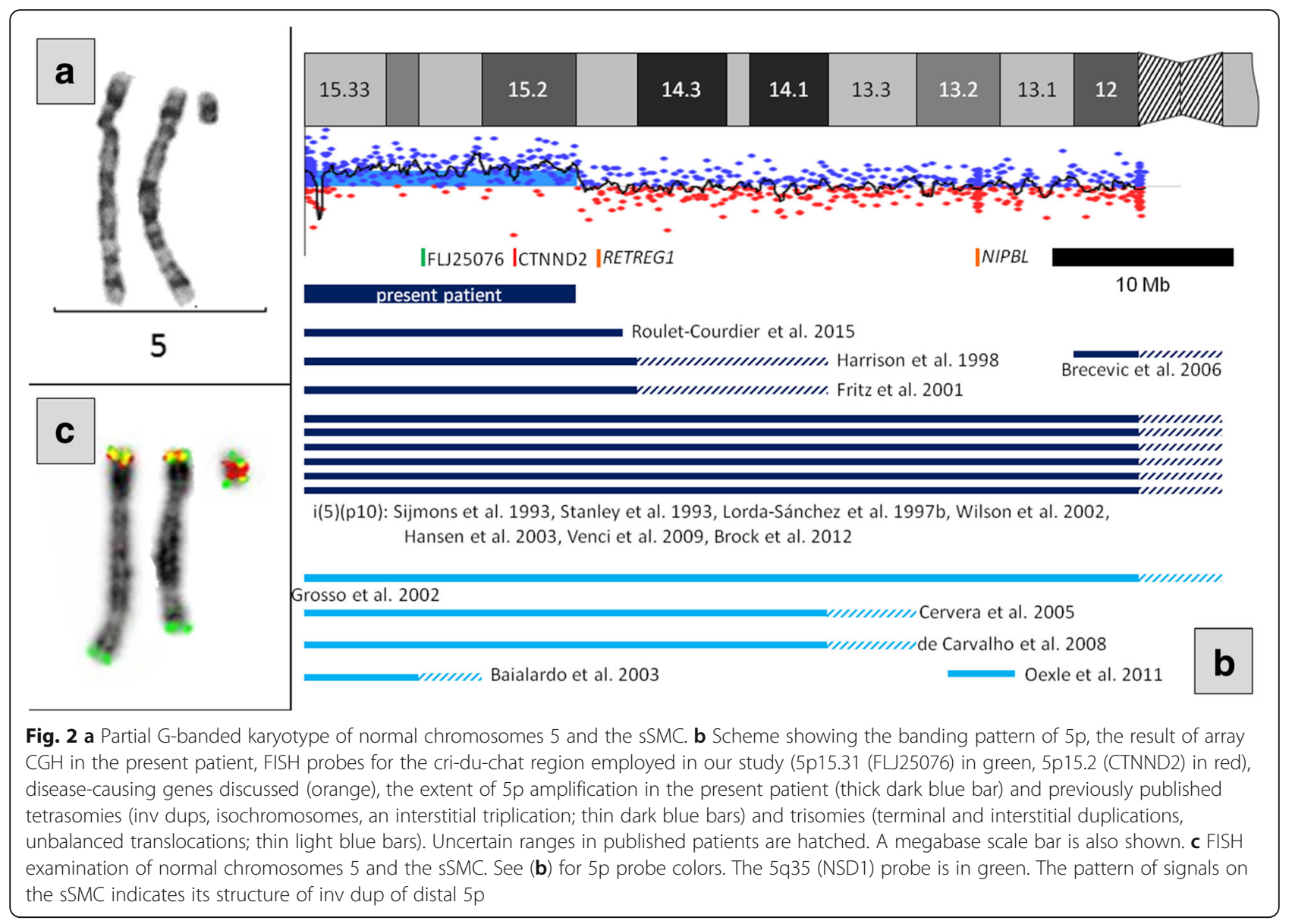

Phenotypes of the tetrasomic patients are similar and only few unspecific differences can be observed (Additional file 2). Recurrent respiratory infections were observed in our patient and in two other patients with distal $5 p$ tetrasomy $[10,11]$, and another patient died at the age of 35 days because of bronchopneumonia [9]. Respiratory infections were also described in a patient with mos $\mathrm{i}(5)(\mathrm{p} 10)$ [4]. A possible explanation for this feature was proposed in a patient with trisomy of the whole $5 p$ by Grosso et al. [19], who found low level of secretory immunoglobulins A (IgA). Nevertheless, detailed immunological examination was not performed and the finding could be coincidental. Patients with $5 p$ tetrasomy published in the literature were not tested for IgA and in our patient it was within the normal range. More detailed immunological examination of patients with $5 p$ amplifications is needed to elucidate the cause of recurrent infections.

Compared to the other patients with distal $5 p$ tetrasomy [9-11], the tetrasomy in our patient does not encompass six of their amplified genes. The previous patients manifested seizures in infancy but our patient did not, and thus one of these genes could cause the seizures. Inactivating RETREG1 mutations cause autosomal recessive hereditary sensory and autonomic neuropathy IIB (OMIM \#613115), but our patient does not show this phenotype. No diseases are associated with the other genes. While the FBXL7 [20], MARCH11 [21], ZNF622 [22], and BASP1 [23] genes are expressed in brain and could possibly contribute to seizures, no data exist on MYO10 expression in CNS.

The comparison of phenotypes associated with $5 p$ tetrasomy and $5 p$ trisomy is summarized in Additional file 3. The common features of all $5 \mathrm{p}$ amplifications are anomalies of CNS, hypotonia, seizures, and ID. Although the critical region of the $5 \mathrm{p} 13.2$ duplication syndrome is involved neither in the tetrasomic region of our patient nor in the distal $5 p$ tetrasomy regions of the previous patients [9-11], many of their traits are similar to those of patients with the $5 \mathrm{p} 13.2$ duplication syndrome, including congenital heart defects and seizures (in two and three of the four distal $5 p$ tetrasomy patients, respectively). The presence of these symptoms in patients with tetrasomies not involving NIPBL indicates that other gene(s) for these conditions may exist in 5p14 and 5p15. Phenotypic overlap among carriers of amplifications of non-overlapping regions of $5 p$ was noted by Cervera et al. [24]. Their patient with dup(5)(p13.3p15.3) had severe 
ID, seizures, macrocephaly, upslanted palpebral fissures, epicanthal folds, depressed nasal bridge, and abnormal pinna, which are also characteristic for the 5p13.2 duplication syndrome. Also de Carvalho et al. [25] reported $\mathrm{t}(5 ; 15)$ (p13.3; 12$)$ leading to distal $5 \mathrm{p}$ trisomy in five individuals with features resembling the $5 \mathrm{p} 13.2$ duplication syndrome. This reopens the question if the $5 p$ trisomy phenotype is caused solely by trisomy of $5 \mathrm{p} 13.2$ with $N I P B L$ as the possible candidate gene [26]. Conversely, also a normal individual with a terminal $5 \mathrm{p}$ trisomy resulting from $\operatorname{der}(15) \mathrm{t}(5 ; 15)(\mathrm{p} 15.1 ; \mathrm{p} 13)$ was reported [27].

The tetrasomy in our patient affected a total of 137 genes. Extensive data collected on their disease involvement, expression and sensitivity to variation are in Additional file 1 . The majority of the protein-coding genes are expressed in all tissues including the brain, and some of them show lack of tolerance to loss-offunction variation. Evidence for sensitivity to increased copy number is generally sparser, and the ClinGen Dosage Sensitivity Map (https://www.ncbi.nlm.nih.gov/projects/dbvar/clingen/) indicates triplosensitivity in none of these genes. Evidence exists for haploinsufficiency of TERT and CTNND2, but neither the phenotype caused by the loss of these genes nor a "mirror" phenotype could be observed in our patient. The TRIO gene has the strongest evidence for haploinsufficiency and causes autosomal dominant mental retardation 44 (MRD44, OMIM \#617061). Our patient and also other patients with $5 p$ tetrasomy showed some features of this disorder such as downslanting palpebral fissures, short nose, micrognathia, facial asymmetry, large ears, clinodactyly, feeding difficulties, developmental delay, ID, poor speech, autistic features and recurrent infections, while microcephaly and seizures are present only in some of them [9-11].

Moreover, according to the STRING database (https:// string-db.org/), the TRIO protein activates RAC1, and the $R A C 1$ gene causes autosomal dominant mental retardation 48 (MRD48, OMIM \#617751) with a very variable phenotype. Other possibly interesting protein interactions may exist. For example, the NDUFS6 gene amplified in our patient encodes the NADH:ubiquinone oxidoreductase subunit S6 of the mitochondrial complex I (MCI). Biallelic NDUFS6 mutations cause MCI deficiency (OMIM \#252010) but no evidence exists for the sensitivity of this gene to amplification. A duplication of NDUFS4, an interaction partner of NDUFS6, in case 331431 from DECIPHER was considered to be possibly pathogenic. The phenotype and severity of MCI deficiency is highly variable and it is difficult to decide if the phenotype of our patient could fit at least partly this condition because of his rather unspecific symptoms; his phenotype is definitely not discordant with mild MCI deficiency. Similarly, the product of MED10 is a component of the Mediator complex, a coactivator for DNAbinding factors activating transcription by RNA polymerase II [28]. Mutations in a possible interacting partner of MED10, MED12, cause X-linked ID (OMIM \#309520, \#300895, \#305450). Another highly interconnected protein encoded by the $\mathrm{SSMC}$ is CCT5, a subunit of the chaperonin containing TCP1 complex involved in folding of cytoskeletal proteins. Multiple subunits of this complex have been associated with various neurodevelopmental disorders $[29,30]$. It must be noted that it is unclear from in silico analysis how much the levels of proteins encoded by genes in the amplified interval are changed, if these changes cause any disturbances of stechiometric ratios in the protein complexes, and if these disturbances impair the functions of these complexes.

As the sSMC does not contain the normal chromosome 5 centromere, it is likely to carry a neocentromere (reviewed in [31]). A variable postzygotic mitotic stability of the $\mathrm{SSMC}$ in individual tissues (possibly due to the differences in the time of neocentromere activation [32]) or a different proliferation disadvantage of different cell types with the sSMC could cause the different level of mosaicism observed in lymphocytes and buccal cells of our patient. The SNP array $\mathrm{CGH}$ analysis revealed the paternal origin of the $\mathrm{SSMC}$ and showed that the two copies of distal $5 \mathrm{p}$ present on the $\mathrm{sSMC}$ are identical with the corresponding part of the normal paternal chromosome 5 present in the patient. This could point to the paternal meiotic origin of the sSMC from an acentric fragment via hairpin formation, reduplication and neocentromere acquisition described by Murmann et al. [32]. In contrast to usually non-mosaic 5p trisomies, the phenotype of $5 p$ tetrasomy due to a sSMC can be influenced by the level of mosaicism. Three patients with mosaic $\mathrm{i}(5)(\mathrm{p} 10)$ in fibroblasts but a normal karyotype in lymphocytes were reported. A girl had a $62 \%$ mosaic of $\mathrm{i}(5)(\mathrm{p} 10)$ in fibroblasts and developmental delay, seizures, mild ID and hypotonia [3]. Another girl with a milder phenotype (borderline intelligence and psychomotor skills, but with complex partial seizures) had only $10 \%$ mosaic in fibroblasts [6]. Finally, a boy having in addition ventriculomegaly, short stature, and macrocephaly, had a $14 \%$ mosaic in fibroblasts [8]. All three children exhibited mosaic hyperpigmentation of skin, and therefore the biopsy should target the hypo- or hyperpigmented lesions generally following the lines of Blaschko [33]. Skin biopsy can be replaced by buccal smear but if the examination is negative and the suspicion for mosaicism persists, invasive sampling is necessary to reach the diagnosis. Because aCGH cannot distinguish trisomy from $50 \%$ mosaic of tetrasomy, FISH should be used to elucidate the type of aberration. However, in contrast to $\mathrm{i}(5)(\mathrm{p} 10)$ cases, skin signs of 
mosaicism have not been observed in patients with mosaic distal $5 p$ tetrasomy. The pitfalls of mosaicism are illustrated also by an infertile man with no dysmorphic features, ID nor congenital defects who carried mos i(5) (p10) in $16 \%$ of lymphocytes, but no such sSMC in skin fibroblasts and urothelial cells [7]. The similarly low level of mosaicism in lymphocytes of our patient initially also shed doubts on its causality, until the buccal analysis was performed which showed a much higher percentage of cells carrying the sSMC. Similarly to PallisterKillian syndrome with supernumerary isochromosome $12 \mathrm{p}$ in skin fibroblasts (and other tissues), but with no or insignificant representation in lymphocytes [34], our case showed that the examination of another tissue is essential, and the easily accessible buccal cells could serve this aim. The decision if the sSMC is causal or if it is just a coincidental finding not explaining the phenotype is very important as it is crucial for planning of possible additional examinations.

\section{Additional files}

Additional file 1: Table S1. Detailed description of encompassed genes. (XLS $328 \mathrm{~kb}$ )

Additional file 2: Table S2. Comparison of clinical features of patients with $5 p$ tetrasomies. (XLS $41 \mathrm{~kb}$ )

Additional file 3: Table S3. Comparison of phenotypes caused by distal $5 p$ tetrasomy, i(5)(p10) and dup5p13.2. (XLS $42 \mathrm{~kb}$ )

\section{Abbreviations}

aCGH: Array comparative genomic hybridization; CNS: Central nervous system; FISH: Fluorescence in situ hybridization; inv dup: Inverted duplication; SNP: Single nucleotide polymorphism; SSMC: Small supernumerary marker chromosome

\section{Acknowledgements}

We thank the patient and the parents for their cooperation.

\section{Funding}

The work was supported by grants 17-29423A, 15-33041A, 00064203 (project IP6003) by Czech Ministry of Health and TA01010931 by Technology Agency of the Czech Republic.

\section{Authors' contributions}

All authors have actively participated in the study and manuscript preparation. Clinical analysis: MKu, MKy, RKP, MV. Anthropological analysis: VM. Laboratory analysis: MS, JD, TR. Manuscript writing and revision: PT, RKP, JD, DN, EK, ZS, MV. All authors read and approved the final manuscript.

\section{Ethics approval and consent to participate}

Written informed consent was obtained from the parents of the patient for publication of this Case Report and any accompanying images. The consent form was approved by the ethical committee of University Hospital Motol, Prague, Czech Republic. All procedures were performed in accordance with the Declaration of Helsinki.

\section{Consent for publication}

Informed written consent was obtained from parents for publication for images and other clinical information relating to this case to be reported for academic purpose

\section{Competing interests}

The authors declare that they have no competing interests.

\section{Publisher's Note}

Springer Nature remains neutral with regard to jurisdictional claims in published maps and institutional affiliations.

\section{Author details}

'Department of Biology and Medical Genetics, Charles University 2nd Faculty of Medicine and University Hospital Motol, V Uvalu 84, 15006 Prague 5,

Czech Republic. ${ }^{2}$ Department of Paediatric Neurology, Charles University 2nd Faculty of Medicine and University Hospital Motol, V Uvalu 84, 15006 Prague 5, Czech Republic. ${ }^{3}$ Department of Radiology, Charles University 2nd Faculty of Medicine and University Hospital Motol, V Uvalu 84, 15006 Prague 5,

Czech Republic.

Received: 5 February 2018 Accepted: 20 April 2018

Published online: 09 May 2018

\section{References}

1. Liehr T, Klein E, Mrasek K, Kosyakova N, Guilherme RS, Aust N, et al. Clinical impact of somatic mosaicism in cases with small supernumerary marker chromosomes. Cytogenet Genome Res. 2013;139:158-63.

2. Sijmons $\mathrm{RH}$, Leegte $B$, van Lingen RA, de Pater JM, van der Veen AY, del Canho $\mathrm{H}$, et al. Tetrasomy $5 p$ mosaicism in a boy with delayed growth, hypotonia, minor anomalies, and an additional isochromosome $5 p[46, X Y$ / 47,XY, + i(5p)]. Am J Med Genet. 1993:47:559-62.

3. Stanley WS, Powell CM, Devine GC, Ellingham T, Samango-Sprouse CA, Vaught DR, et al. Mosaic 5p tetrasomy. Am J Med Genet. 1993;45:774-6.

4. Lorda-Sánchez I, Villa A, Urioste M, Bernal E, Jaso E, García A, Martínez-Frías ML. Tetrasomy $5 p$ mosaicism due to an extra i $(5 p)$ in a severely affected girl. Am J Med Genet. 1997;68:481-4

5. Wilson SC, Susman M, Bain S, Wohlferd M, Van Dyke D, Daniel A, et al. Isochromosome $5 p$ mosaicism at prenatal diagnosis: observations and outcomes in six cases at chorionic villus sampling and one at amniocentesis. Prenat Diagn. 2002;22:681-5.

6. Hansen LK, Brandrup F, Rasmussen K. Pigmentary mosaicism with mosaic chromosome 5p tetrasomy. Br J Dermatol. 2003;149:414-6.

7. Venci A, Bettio D. Tetrasomy $5 p$ mosaicism due to an additional isochromosome $5 p$ in a man with normal phenotype. Am J Med Genet A. 2009;149A:2889-91.

8. Brock JA, Dyack S, Ludman M, Dumas N, Gaudet M, Morash B. Mosaic tetrasomy $5 p$ resulting from an isochromosome $5 p$ marker chromosome: case report and review of literature. Am J Med Genet A. 2012;158A:406-11.

9. Harrison KJ, Teshima IE, Silver MM, Jay V, Unger S, Robinson WP, et al. Partial tetrasomy with triplication of chromosome (5) (p14-p15.33) in a patient with severe multiple congenital anomalies. Am J Med Genet. 1998;79:103-7.

10. Fritz B, Dietze I, Wandall A, Aslan M, Schmidt A, Kattner E, et al. A supernumerary marker chromosome with a neocentromere derived from 5p14->pter. J Med Genet. 2001;38:559-65.

11. Roulet-Coudrier F, Rouibi A, Thuillier C, Bourthoumieu S, Lebbar A, Dupont JM, Yardin C. Unusual isochromosome 5p marker chromosome. Am J Med Genet A. 2015:167A:455-9.

12. Brecevic L, Michel S, Starke H, Müller K, Kosyakova N, Mrasek K, et al. Multicolor FISH used for the characterization of small supernumerary marker chromosomes (SSMC) in commercially available immortalized cell lines. Cytogenet Genome Res. 2006;114:319-24.

13. Lorda-Sánchez I, Urioste M, Villa A, Carrascosa MC, Vázquez MS, Martínez A, Martínez-Frías ML. Proximal partial 5p trisomy resulting from a maternal (19; 5) insertion. Am J Med Genet. 1997;68:476-80.

14. Chia NL, Bousfield LR, Johnson BH. A case report of a de novo tandem duplication (5p) (p14__-pter). Clin Genet. 1987;31:65-9.

15. Loscalzo ML, Becker TA, Sutcliffe M. A patient with an interstitial duplication of chromosome $5 p 11-p 13.3$ further confirming a critical region for $5 p$ duplication syndrome. Eur J Med Genet. 2008;51:54-60.

16. Yan J, Zhang F, Brundage E, Scheuerle A, Lanpher B, Erickson RP, et al. Genomic duplication resulting in increased copy number of genes encoding the sister chromatid cohesion complex conveys clinical consequences distinct from Cornelia de Lange. J Med Genet. 2009;46: 626-34

17. Novara F, Alfei E, D'Arrigo S, Pantaleoni C, Beri S, Achille V, et al. 5 p13 microduplication syndrome: a new case and better clinical definition of the syndrome. Eur J Med Genet. 2013;56:54-8. 
18. Valli R, Maserati E, Marletta C, Pressato B, Lo Curto F, Pasquali F. Evaluating chromosomal mosaicism by array comparative genomic hybridization in hematological malignancies: the proposal of a formula. Cancer Genet. 2011; 204:216-8.

19. Grosso S, Cioni M, Garibaldi G, Pucci L, Galluzzi P, Canapicchi R, et al. De novo complete trisomy $5 \mathrm{p}$ : clinical and neuroradiological findings. Am J Med Genet. 2002;112:56-60.

20. Nagase T, Ishikawa K, Suyama M, Kikuno R, Hirosawa M, Miyajima N, et al. Prediction of the coding sequences of unidentified human genes. XII. The complete sequences of 100 new CDNA clones from brain which code for large proteins in vitro. DNA Res. 1998:5:355-64.

21. Morokuma Y, Nakamura N, Kato A, Notoya M, Yamamoto Y, Sakai Y, et al. MARCH-XI, a novel transmembrane ubiquitin ligase implicated in ubiquitindependent protein sorting in developing spermatids. J Biol Chem. 2007;282: 24806-15.

22. Seong HA, Gil M, Kim KT, Kim SJ, Ha H. Phosphorylation of a novel zincfinger-like protein, ZPR9, by murine protein serine/threonine kinase 38 (MPK38). Biochem J. 2002;361:597-604.

23. Park S, Kim Yl, Kim B, Seong C, Oh Y, Baek K, Yoon J. Characterization of bovine and human CDNAs encoding NAP-22 (22 kDa neuronal tissueenriched acidic protein) homologs. Mol Cells. 1998;8:471-7.

24. Cervera M, Sánchez S, Molina B, Alcántara MA, Del Castillo V, Carnevale A, et al. Trisomy of the short arm of chromosome 5 due to a de novo inversion and duplication (5)(p15.3 p13.3). Am J Med Genet A. 2005;136A:381-5.

25. de Carvalho AF, da Silva Bellucco FT, Kulikowski LD, Toralles MB, Melaragno Ml. Partial $5 p$ monosomy or trisomy in 11 patients from a family with a $t(5$; 15)(p13.3;p12) translocation. Hum Genet. 2008;124:387-92.

26. Oexle $\mathrm{K}$, Hempel $\mathrm{M}$, Jauch $\mathrm{A}$, Meitinger T, Rivera-Bruqués $\mathrm{N}$, StengelRutkowski S, Strom T. 3.7 Mb tandem microduplication in chromosome 5p13.1-p13.2 associated with developmental delay, macrocephaly, obesity, and lymphedema. Further characterization of the dup(5p13) syndrome. Eur J Med Genet. 2011;54:225-30.

27. Baialardo EM, Torrado Mdel V, Barreiro CZ, Gallego MS. Partial distal $5 p$ trisomy resulting from paternal translocation $(5 ; 15)(p 15.1 ;$ p13) in a boy with no mental retardation. Clin Dysmorphol. 2003:12:257-9.

28. Sato S, Tomomori-Sato C, Banks CAS, Sorokina I, Parmely TJ, Kong SE, et al. Identification of mammalian mediator subunits with similarities to yeast mediator subunits Srb5, Srb6, Med11, and Rox3. J Biol Chem. 2003;278: 15123-7.

29. Iossifov I, Levy D, Allen J, Ye K, Ronemus M, Lee YH, et al. Low load for disruptive mutations in autism genes and their biased transmission. Proc Natl Acad Sci U S A. 2015;112:E5600-7.

30. Krishnan A, Zhang R, Yao V, Theesfeld CL, Wong AK, Tadych A, et al. Genome-wide prediction and functional characterization of the genetic basis of autism spectrum disorder. Nat Neurosci. 2016;19:1454-62.

31. Scott KC, Sullivan BA. Neocentromeres: a place for everything and everything in its place. Trends Genet. 2014;30:66-74.

32. Murmann AE, Conrad DF, Mashek H, Curtis CA, Nicolae RI, Ober C, Schwartz S. Inverted duplications on acentric markers: mechanism of formation. Hum Mol Genet. 2009:18:2241-56.

33. Thomas IT, Frias JL, Cantu ES, Lafer CZ, Flannery DB, Graham JG Jr. Association of pigmentary anomalies with chromosomal and genetic mosaicism and chimerism. Am J Hum Genet. 1989:45:193-205.

34. Peltomaki P, Knuutila S, Ritvanen A, Kaitila I, de la Chapelle A. Pallister-Killian syndrome: cytogenetic and molecular studies. Clin Genet. 1987;31:399-405.

\section{Ready to submit your research? Choose BMC and benefit from:}

- fast, convenient online submission

- thorough peer review by experienced researchers in your field

- rapid publication on acceptance

- support for research data, including large and complex data types

- gold Open Access which fosters wider collaboration and increased citations

- maximum visibility for your research: over $100 \mathrm{M}$ website views per year

At BMC, research is always in progress.

Learn more biomedcentral.com/submissions 